\title{
Incidência de Aspergillus Seção Nigri Produtores de Ocratoxina A em Uvas Syrah Cultivadas em Regiões Vitícolas do Brasil
}

\begin{abstract}
Fabiana Franca Reines Passamani (I), Thaiana Marinha de Almeida Sousa (I), giuliano Elias Pereira (II,II), Luis Roberto Batista (I)

(I) UFLA - Universidade Federal de Lavras (UNIVERSIDADE FEDERAL DE LAVRAS Câmpus Universitário, Caixa Postal 3037, CEP 3720), (II) EMBRAPA - Empresa Brasileira de Pesquisa agropecuária (Rodovia BR-428, Km 152, Zona Rural - Caixa Postal 23 CEP: 56302-970 -
\end{abstract}

Petrolina)

\section{Resumo}

Os fungos Aspergillus Seção Nigri são relatados como as principais espécies contaminantes de uvas viníferas em diferentes regiões do mundo, especialmente as situadas na zona temperada. Dentre estes o A. carbonarius é o principal produtor de uma toxina, a ocratoxina A (OTA). O perfil de produção da OTA pode ser afetado sob diferentes condições de cultivo do fungo, tais como disponibilidade de água, nutrientes, $\mathrm{pH}$ e temperatura. Nesse sentido, o presente estudo teve como objetivo avaliar a ocorrência de fungos Aspergillus Seção Nigri em uvas cultivadas em São Paulo, Minas Gerais e no Vale do Submédio do São Francisco, analisando as diferenças observadas entre as regiões. Para isso foram coletadas 54 amostras de uvas (Vitis vinifera) da variedade Syrah em 2011 e 2012. As bagas e as sementes foram plaqueadas em meio DRBC, com desinfecção superficial e, avaliadas quanto ao percentual de contaminação por Aspergillus Seção Nigri. Também foi analisada a freqüência de ocorrência das espécies desse grupo. Os resultados obtidos mostram que não existe diferença estatística significativa entre as regiões de São Paulo e de Minas Gerais para a Syrah, mas essas regiões são diferentes estatisticamente do Vale do Submédio São Francisco, onde se observou o maior percentual de contaminação. Os menores percentuais de contaminação foram encontrados na região de São Paulo. Não foi identificada nenhuma espécie de fungo ocratoxigênico nas

\footnotetext{
Referência:

Fabiana Franca Reines Passamani, Thaiana Marinha de Almeida Sousa, giuliano Elias Pereira, Luis Roberto Batista. Incidência de Aspergillus Seção Nigri Produtores de Ocratoxina A em Uvas Syrah Cultivadas em Regiões Vitícolas do Brasil. In: Anais do 12 Congresso Latinoamericano de Microbiologia e Higiene de Alimentos - MICROAL 2014 [= Blucher Food Science Proceedings, num.1, vol.1]. São Paulo: Editora Blucher, 2014. 
vinícolas situadas na região Sudeste do Brasil. Na região Nordeste 1,3\% e $13 \%$ das espécies foram identificadas como produtoras de OTA nas safras de 2011 e 2012, respectivamente. AGRADECIMENTOS: CNPq, FAPEMIG, EMBRAPA Semiárido e aos Vitivinicultores.

Palavras-Chave: Aspergillus, Micotoxina, uvas Agência de Fomento: 